\title{
Difference in suicide methods used between suicide attempters and suicide completers
}

\author{
Meerae Lim', Sang Uk Lee ${ }^{2}$ and Jong-lk Park ${ }^{3^{*}}$
}

\begin{abstract}
Background: In light of the increased suicide rate in Korea, it has become important for researchers to examine the various factors associated with it. The purpose of this study is to compare and analyze the difference between suicide attempters and completers in terms of the suicide methods used and the lethality of these methods. In addition, we investigated certain demographic factors that are associated with the choice of suicide method by evaluating their lethality.

Finding: The most frequently used methods of suicide were different in the two groups of attempters and completers. Drug poisoning was the most frequent method in suicide attempters, whereas hanging was the most common method among suicide completers. Drug poisoning, stabbing, and other chemical poisoning were evaluated as relatively non-lethal compared to other suicide methods. While about $70.0 \%$ of the suicide attempters used relatively non-lethal methods, almost all suicide completers used lethal methods, based on our classification of the lethality of the method. In terms of gender, males used more lethal methods of suicide.

Conclusions: Suicide completers' choice of suicide methods are different from those of suicide attempters and tend to be more lethal. Interventions to restrict access to more lethal suicidal methods could be a useful strategy to reduce the suicide rates in South Korea.
\end{abstract}

Keywords: Suicide, Suicide method, Lethality, Suicide attempters, Suicide completers

Suicide is a serious social problem in Korea. Data from Korea's National Statistics Office published in September 2013 states that the total number of deaths in the previous year was 14,160 and that suicide was the fourth leading cause of death. Korea has the highest suicide rate i.e., 29.1 per 100,000, from the member countries of the Organization for Economic Cooperation and Development where the average suicide rate is 12.5 per 100,000 [1].

Little is known about why the suicide rate has increased so rapidly in Korea. The risk factors are very complex and interwoven. Therefore, we chose to focus on the lethality of the suicide methods used and their association with the increasing suicide rate. Previous research has pointed to the link between suicide methods and the rate of suicide. Spicer and Miller [2] showed that the particular suicide method chosen is strongly linked to suicide completion. Another study showed that the use of specific suicide

\footnotetext{
* Correspondence: lugar@kangwon.ac.kr

${ }^{3}$ Department of Psychiatry, Kangwon National University School of Medicine,

17-1 Hyoja-3-Dong, Chuncheon-Si, Kangwon-Do 200-947, Korea

Full list of author information is available at the end of the article
}

methods such as hanging, is reflected in the increased suicide rate in Korea [3]. Studies on suicide in Asia suggest that the availability of fatal suicide methods can increase suicide rates [4].

The purpose of this paper is to compare and analyze the difference between suicide attempters and completers in terms of the suicide methods used. In addition, we investigated the association of certain demographic factors with the choice of suicide method in terms of their lethality.

In this study, we collected and analyzed two kinds of secondary data. First, we obtained the results of a nationwide survey on suicide attempters, which was done as a pilot study of Korean Nationwide Suicide Survey (KNSS) based on law. Data on suicide attempts that occurred nationwide between July 6, 2012 and November 25, 2012 were collected. A suicide attempt was defined as "a self-destructive behavior with intent to end one's life independent of resulting damage" [5]. Attempters from this list who died upon arrival at the hospital were excluded from the analysis. Data were collected by reviewing the medical records in seven university 
hospitals: Boramae Medical Center, Seoul; Seoul National University Bundang Hospital, Gyeonggi-do; Kangwon National University Hospital, Gangwon-do; Eulgi University Hospital, Choonchung-do; Chonnam National University Hospital, Chonra-do; Busan National University Hospital, Gyeongsang-do; and Gueongsang National University Hospital, after obtaining ethical approval from the institutional review board (IRB).

The second data source was the "Statistics of cause of death, 2012" records which was public data published by Statistics Korea. We analyzed the data concerning deaths by suicide that occurred between July 6, 2012 and November 25, 2012, the same period under analysis in the previous data set of medical records of suicide attempts.

From these two data sets, we gathered information about age, gender, marital status, degree of education, and method of suicide or suicide attempt. In case of attempters, we could gather information about medical results of suicide attempt in addition to suicide methods. Medical results were evaluated by Colombia Suicide Severity Rating Scale (C-SSRS) lethality subscale [6].

Data were analyzed using SPSS 18.0 for Windows (SPSS Inc., Chicago, IL, USA). Each method of suicide was analyzed separately in relation to suicide attempt and suicide completion. We evaluated the lethality of each suicide method in two ways. First, we used the C-SSRS lethality subscale to rate lethality of each suicide method. With this scale, lethality is appraised on a six-point Likert scale, with responses ranging from 0 (no physical damage) to 5 (death) [6]. Second, we developed a "lethality ratio" that is defined as the ratio of the percentage of the

Table 1 Comparison of methods of suicide between suicide attempters and suicide completers

\begin{tabular}{|c|c|c|c|c|c|}
\hline & \multicolumn{2}{|c|}{$\begin{array}{c}\text { Suicide } \\
\text { attempters }\end{array}$} & \multicolumn{2}{|c|}{$\begin{array}{c}\text { Suicide } \\
\text { completers }\end{array}$} & \multirow[t]{2}{*}{ Statistics } \\
\hline & $\mathbf{N}$ & $\%$ & $\mathbf{N}$ & $\%$ & \\
\hline Drug poisoning & 248 & 49.6 & 56 & 1.0 & \multirow{12}{*}{$\begin{array}{c}x^{2}=2784.2^{a} \\
p<.001\end{array}$} \\
\hline Gas poisoning & 34 & 6.8 & 392 & 7.3 & \\
\hline Pesticide or herbicide & 74 & 14.8 & 741 & 13.8 & \\
\hline $\begin{array}{c}\text { Other chemical } \\
\text { poisoning }\end{array}$ & 20 & 4.0 & 138 & 2.6 & \\
\hline Hanging & 25 & 5.0 & 2810 & 52.2 & \\
\hline Drowning & 4 & 0.8 & 207 & 3.8 & \\
\hline Gun suicide & 0 & 0.0 & 6 & 0.1 & \\
\hline Immolation & 0 & 0.0 & 19 & 0.3 & \\
\hline Stabbing & 77 & 15.4 & 35 & 0.6 & \\
\hline Jumping & 18 & 3.6 & 953 & 17.7 & \\
\hline Others & 0 & 0.0 & 32 & 0.6 & \\
\hline Total & 500 & 100.0 & 5388 & 100.0 & \\
\hline
\end{tabular}

${ }^{\mathrm{a}}$ Drowning, gun suicide, immolation, others was excluded from the analysis because that expected frequencies were below than 5 .
Table 2 Comparison of methods of suicide by gender

\begin{tabular}{|c|c|c|c|c|c|c|}
\hline & \multicolumn{2}{|c|}{ Male } & \multicolumn{2}{|c|}{ Female } & \multicolumn{2}{|c|}{ Total } \\
\hline & $\mathrm{N}$ & $\%$ & $\mathrm{~N}$ & $\%$ & $\mathrm{~N}$ & $\%$ \\
\hline Drug poisoning & 68 & 32.5 & 180 & 61.9 & 248 & 49.6 \\
\hline Gas poisoning & 27 & 12.9 & 7 & 2.4 & 34 & 6.8 \\
\hline Pesticide or herbicide & 52 & 24.9 & 22 & 7.6 & 74 & 14.8 \\
\hline Other chemical poisoning & 7 & 3.3 & 13 & 4.5 & 20 & 4.0 \\
\hline Hanging & 13 & 6.2 & 12 & 4.1 & 25 & 5.0 \\
\hline Drowning & 2 & 1.0 & 2 & 0.7 & 4 & 0.8 \\
\hline Stabbing & 33 & 15.8 & 44 & 15.1 & 77 & 15.4 \\
\hline Jumping & 7 & 3.3 & 11 & 3.8 & 18 & 3.6 \\
\hline Total & 209 & 100.0 & 291 & 100.0 & 500 & 100.0 \\
\hline
\end{tabular}

specific method used by suicide completers to the percentage of the specific method used by suicide attempters. To examine the gender difference in the choice of suicide method, we used a binary logistic regression and adjusted for age, marital status, and level of education.

A total of 502 medical records of suicide attempters were included in this study. The average age of the participants was 43.05 years $( \pm 18.52)$, with ages ranging from 13 to 95 years. There were more females $(58.4 \%$, $n=293)$ than males $(41.6 \%, n=209)$.

Table 1 shows the frequency of each method of suicide for suicide attempters. The most commonly used method for suicide attempters was poisoning by prescribed drug overdose $(49.6 \%, n=248)$, followed by wrist cutting $(15.4 \%$, $n=77)$, and pesticide poisoning $(14.8 \%, n=74)$. Table 2 shows the gender differences in the choice of method for suicide attempts. While drug poisoning was the method preferred mostly in females, pesticide, herbicide, and gas poisoning were methods preferred in males.

Table 3 Lethality of the method used for attempting suicide

\begin{tabular}{|c|c|c|c|}
\hline & \multicolumn{2}{|c|}{ C-SSRS ${ }^{\text {a }}$ Lethality subscale } & \multirow{2}{*}{$\begin{array}{c}\text { Lethality } \\
\text { ratio }^{\mathbf{b}}\end{array}$} \\
\hline & Mean & Standard deviation & \\
\hline Drug poisoning & 2.48 & 0.92 & 2.0 \\
\hline Gas poisoning & 3.00 & 1.00 & 107.3 \\
\hline Pesticide or herbicide & 3.44 & 1.16 & 93.2 \\
\hline Other chemical poisoning & 2.00 & 0.85 & 65.0 \\
\hline Hanging & 3.00 & 1.16 & 1044.0 \\
\hline Drowning ${ }^{c}$ & & & 475.0 \\
\hline Stabbing & 2.39 & 0.98 & 3.9 \\
\hline Jumping & 4.07 & 1.77 & 491.7 \\
\hline
\end{tabular}

${ }^{a} \mathrm{C}-$ SSRS: Colombia Suicide Severity Rating Scale.

bethality ratio: (\% of the specific suicide method used by suicide completers)/ (\% of the specific suicide method used by suicide attempters).

'Among the 502 suicide attempters, 4 attempters used drowning as a suicide method. Only 1 participant from among them answered the C-SSRS lethality subscale. That particular score is not representative and therefore, we excluded this score from this table. 
Table 4 Comparison of the choice of suicide methods between males and females

\begin{tabular}{cccccc}
\hline & $\begin{array}{c}\text { Non-lethal } \\
\text { method }\end{array}$ & $\begin{array}{c}\text { Lethal } \\
\text { method }\end{array}$ & Total & Exp(B) & 95\% C.I. \\
\hline Male & $101(48.8 \%)$ & $106(51.2 \%)$ & $207(100.0 \%)$ & 3.75 & $2.30 \sim 6.12$ \\
Female & $224(77.5 \%)$ & $65(22.5 \%)$ & $289(100.0 \%)$ & Reference & \\
Total & $325(65.5 \%)$ & $171(34.5 \%)$ & $496(100.0 \%)$ & & \\
\hline
\end{tabular}

Co-variates: age, marital status, degree of education.

Data from a total of 5,388 suicide completers were analyzed. The mean age of suicide completers was 52.36 years $( \pm 18.31)$, with ages ranging from 12 to 98 years. Unlike suicide attempters, there were more male $(67.2 \%, \mathrm{~N}=3621)$ than female $(32.8 \%, \mathrm{~N}=1767)$ suicide completers. There was a significant gender difference found between the suicide attempter and suicide completer groups $\left(\chi^{2}=132.0, d f=1, p<.01\right)$.

Table 1 also shows the frequency of each method of suicide for suicide completers. The most commonly used method by suicide completers was hanging (52.2\%, $\mathrm{N}=2810$ ), followed by jumping from a height (17.7\%, $\mathrm{N}=953)$, and pesticide poisoning (13.8\%, $\mathrm{N}=741)$. However, the percentage of methods such as drug poisoning and stabbing, which were the first and second most commonly used methods in suicide attempters, was low $(1.0 \%, \mathrm{~N}=56$ and $0.6 \%, \mathrm{~N}=35$ respectively) in suicide completers.

As mentioned in the methods section, we evaluated lethality of each method of suicide in different two ways. According to the C-SSRS lethality subscale ratings, jumping from a height led to the most severe medical damage, followed by pesticide or herbicide poisoning. According to the lethality ratio, hanging was found to be the most lethal suicide method, followed by jumping from a height, and drowning. Drug poisoning and stabbing were relatively less lethal based on these two methods of evaluation (Table 3 ).
For further analysis, we divided the suicide methods used into two groups: lethal and non-lethal. Methods such as drug poisoning, stabbing, and other chemical poisoning, which accounted for relatively less lethal ratings in both evaluations were classified as non-lethal. The rest of the methods were classified as lethal. The analysis of these two groups based on lethality of method showed that $69.6 \%$ of the suicide attempters used non-lethal suicide methods, whereas $95.9 \%$ of the suicide completers used lethal methods $\left(\chi^{2}=2089.5, d f=1\right.$, $p<.01)$.

A binary logistic regression analysis was used to confirm the relationship between gender and choice of suicide method, after adjusting for age, marital status, and degree of education (Table 4). Results showed that males were significantly associated with using lethal suicide methods.

The present study is the first to compare the difference in the methods of suicide between suicide attempters and suicide completers in South Korea. The most frequently used methods of suicide were different for suicide attempters and completers. Drug poisoning was the most frequent used method in suicide attempters, whereas hanging was the most frequently used method in suicide completers. When we arbitrarily classified each method of suicide into one of two groups i.e., lethal and non-lethal, we found that around $70.0 \%$ of the suicide attempters used non-lethal methods and almost all suicide completers used lethal methods, based on our classification of lethality. This result is supported by previous research that showed that the choice of lethal suicide methods is associated with suicidal completion [2-4,7,8].

Another important result of our study is the gender difference between suicide attempters and completers. There were more males in the suicide completers group and more females in the suicide attempters group. This

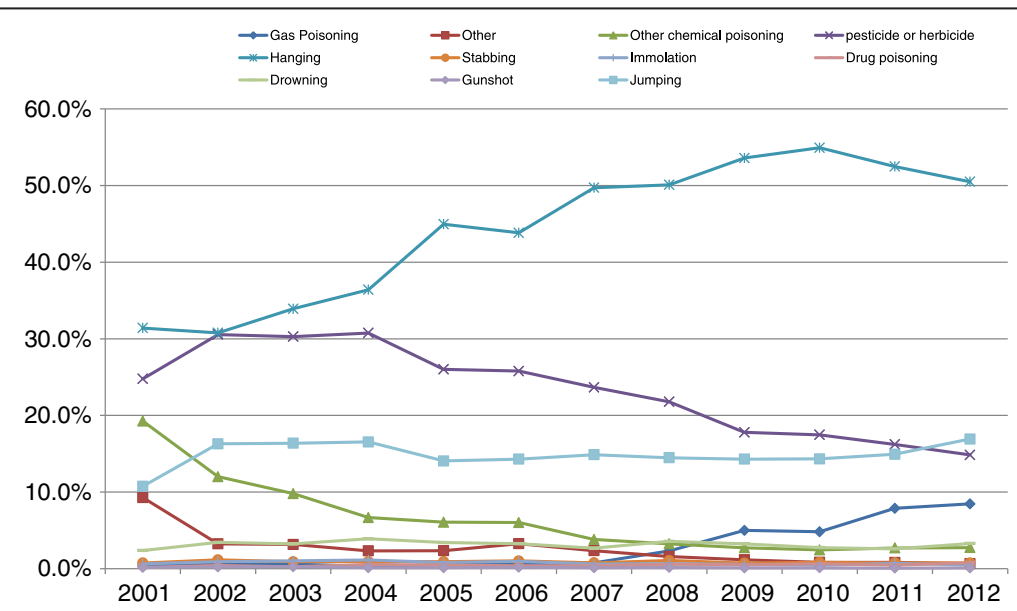

Figure 1 Changes in the methods of suicide used in Korea across time. 
finding is consistent with some previous studies [9-13]. Our findings demonstrate that the disparity between suicide rates and the number of suicide attempts among males and females may be explained by their choice of suicide method.

According to Gunnell et al. [7], the methods of suicide commonly employed are influenced by their availability and access. They also reported that the accessibility and lethality of particular methods of suicide might have profound effects on overall suicide rates. In our study, we also emphasized that the rapid increase in suicide rates in Korea should be attributed in part to the change in suicide methods used over the past 15 years (Figure 1). In particular, the use of lethal suicide methods such as hanging and gas poisoning has increased recently. The rate of use of the suicide method of hanging has steadily increased from $31.4 \%$ in 2001 to $50.5 \%$ in 2012. In addition, the use of gas poisoning has increased 20 times in 2012 as compared to 2001 (from $0.4 \%$ in 2001to 8.5\% in 2012). We still do not know the exact reasons for this increase and decrease in the usage of these suicide methods. However, we can hypothesize that the media has a role to play, especially the vivid and alluring descriptions of celebrity suicides may lead to the Werther effect thereby increasing the rate of copycat suicides using methods such as hanging and gas poisoning $[14,15]$.

\section{Competing interests}

The authors declare that they have no competing interests.

\section{Authors' contributions}

$M L$ participated in the design of the study, performed the statistical analysis and draft the manuscript. SUL participated in collecting data and helped to analyze. JIP conceived of the study, and participated in its design and coordination and helped to draft the manuscript. All authors read and approved the final manuscript.

\section{Acknowledgements}

We thank all 7 hospital psychiatrists who collected data of suicide attempters at each centers.

\section{Author details}

${ }^{1}$ St. Andrea Neuropsychiatric Hospital, Icheon, Republic of Korea. ${ }^{2}$ Korea Suicide Prevention Center, Seoul, Republic of Korea. ${ }^{3}$ Department of Psychiatry, Kangwon National University School of Medicine, 17-1

Hyoja-3-Dong, Chuncheon-Si, Kangwon-Do 200-947, Korea.

Received: 20 October 2014 Accepted: 11 December 2014 Published: 15 December 2014

\section{References}

1. Korea S: Statistics of Cause of Death, 2012; 2013

2. Spicer RS, Miller TR: Suicide acts in 8 states: incidence and case fatality rates by demographics and method. Am J Public Health 2000, 90:1885-1891

3. Park S, Ahn MH, Lee A, Hong JP: Associations between changes in the pattern of suicide methods and rates in Korea, the US, and Finland. Int J Ment Health Syst 2014, 8:22.

4. Beautrais AL: Suicide in Asia. Crisis: J Crisis Interv Suicide Prev 2006, 27:55-57.

5. O'Carroll PW, Berman AL, Maris RW, Moscicki EK, Tanney BL, Silverman MM: Beyond the Tower of Babel: a nomenclature for suicidology. Suicide Life Threat Behav 1996, 26:237-252.
6. Posner K, Brown GK, Stanley B, Brent DA, Yershova KV, Oquendo MA, Currier GW, Melvin GA, Greenhill L, Shen S, Mann JJ: The Columbia-Suicide Severity Rating Scale: initial validity and internal consistency findings from three multisite studies with adolescents and adults. Am J Psychiatry 2011, 168:1266-1277.

7. Gunnell D, Middleton N, Frankel S: Method availability and the prevention of suicide-a re-analysis of secular trends in England and Wales 1950-1975. Soc Psychiatry Psychiatr Epidemiol 2000, 35:437-443.

8. Park S, Cho SC, Kim BN, Kim JW, Yoo HJ, Hong JP: Increased use of lethal methods and annual increase of suicide rates in Korean adolescents: comparison with adolescents in the United States. J Child Psychol Psychiatry 2014, 55:258-263.

9. DeJong TM, Overholser JC, Stockmeier CA: Apples to oranges?: a direct comparison between suicide attempters and suicide completers. $J$ Affect Disord 2010, 124:90-97.

10. Fushimi M, Sugawara J, Saito S: Comparison of completed and attempted suicide in Akita, Japan. Psychiatry Clin Neurosci 2006, 60:289-295.

11. Iribarren C, Sidney S, Jacobs DR Jr, Weisner C: Hospitalization for suicide attempt and completed suicide: epidemiological features in a managed care population. Soc Psychiatry Psychiatr Epidemiol 2000, 35:288-296.

12. Marttunen MJ, Henriksson MM, Aro HM, Heikkinen ME, Isometsa ET, Lonnqvist JK: Suicide among female adolescents: characteristics and comparison with males in the age group 13 to 22 years. J Am Acad Child Adolesc Psychiatry 1995, 34:1297-1307.

13. Evolution 1950-2000 of global suicide rates. [http://www.who.int/mental_ health/prevention/suicide/evolution/en/]

14. Ji NJ, Hong YP, Stack SJ, Lee WY: Trends and risk factors of the epidemic of charcoal burning suicide in a recent decade among Korean People. J Korean Med Sci 2014, 29:1174-1177.

15. Jeong J, Shin SD, Kim H, Hong YC, Hwang SS, Lee EJ: The effects of celebrity suicide on copycat suicide attempt: a multi-center observational study. Soc Psychiatry Psychiatr Epidemiol 2012, 47:957-965.

doi:10.1186/1752-4458-8-54

Cite this article as: Lim et al:: Difference in suicide methods used between suicide attempters and suicide completers. International Journal of Mental Health Systems 2014 8:54.

\section{Submit your next manuscript to BioMed Central and take full advantage of:}

- Convenient online submission

- Thorough peer review

- No space constraints or color figure charges

- Immediate publication on acceptance

- Inclusion in PubMed, CAS, Scopus and Google Scholar

- Research which is freely available for redistribution 